\title{
Analysis of Temporal-Spatial Variation Characteristics of Drought: A Case Study from Xinjiang, China
}

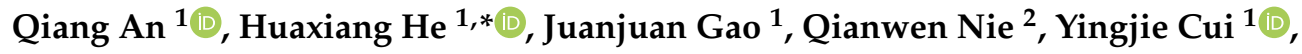 \\ Chuanjiang Wei ${ }^{1}$ and Xinmin Xie ${ }^{1}$ \\ 1 State Key Laboratory of Simulation and Regulation of Water Cycle in River Basin, China Institute of Water \\ Resources and Hydropower Research, Beijing 100038, China; anqiang666@126.com (Q.A.); \\ xiaoxiao.mychoice@163.com (J.G.); cuiyj@iwhr.com (Y.C.); wchj@iwhr.com (C.W.); xiexm@iwhr.com (X.X.) \\ 2 North China Electric Power University, Beijing 102206, China; nieqianwen97@163.com \\ * Correspondence: he6680145@sina.com; Tel.: +86-10-687-857-08
}

Received: 6 February 2020; Accepted: 6 March 2020; Published: 8 March 2020

\begin{abstract}
It is of great significance to study the characteristics and change trends of drought in Xinjiang to provide a basis for implementing local strategies. Based on monthly precipitation and temperature data from 95 meteorological stations in Xinjiang, from 1960 to 2018, the Standardized Precipitation Evapotranspiration Index (SPEI) was calculated, and the characteristics and trends of drought in Xinjiang were analysed, in details. Furthermore, a comprehensive evaluation index, i.e., Regional Drought Severity (RDS), was proposed to analyse the effects of duration of the drought and the extent of the drought affected area. The results from our study suggested: (1) In consideration of global warming, droughts in Xinjiang have intensified during the past 59 years, and the frequency and range of droughts have increased significantly; (2) During the plant growing season, spring, summer, and autumn, a drying trend was observed, while, a wetting trend was identified for winter season; (3) The drought-prone months shifted from January and December to March-November in the 1970s, and April was identified as a month with the highest frequency of droughts; (4) The meteorological change occurred a period near 1997. It can be speculated that the intensified droughts can be triggered by the excessive temperature rise, through comparing the changes in SPEI and the Standardized Precipitation Index (SPI), before and after the meteorological change; (5) After the meteorological change, the frequency of droughts with different levels had significantly increased, in addition, the drought-prone areas shifted from the north-west to the south-east. The results from this research provide important support for drought management in Xinjiang, also offer scientific basis for the formulation of relevant policies on agricultural and animal husbandry production.
\end{abstract}

Keywords: drought characteristics; SPEI; meteorological change; Xinjiang

\section{Introduction}

Drought is a kind of climate phenomenon, characterised by a shortage of water, which is insufficient to meet human survival and economic development. During recent years, due to the global warming, drought events occur more frequently [1,2]. Over the past few decades, droughts in Asia have increased both in frequency and intensity [3]. Influenced by the East Asian monsoon and complex terrain, China suffered long-term and severe droughts in the second half of the 20th century, which had a serious impact on the socio-economic development [4]. There has been a general drying trend over China for the 1950-2006 study period with a concurrent increasing risk of drought [5]. During recent decades, the frequency, duration, and range of drought have been expanding in China [3]. Especially, severe and extreme drought events occur more frequently in northern China [6]. In addition, the drought 
areas also began to expand to the humid and sub-humid areas in the south and east of China, and this trend is likely to continue in future [7].

The main types of drought are meteorological, agricultural, and hydrological droughts. In a broad definition, these droughts occur in a certain order, with meteorological drought occurring first, and then affecting the other two types of drought [2]. Among the various types of drought, the performance of meteorological drought is the most direct and clear [8]. Moreover, hydrological and agricultural droughts have more influencing factors and are more susceptible to human activities. Drought indexes are the basis for reflecting drought situations, and each drought index has its own characteristics, advantages, and disadvantages. In consideration of global warming, the indexes considering potential evapotranspiration (PET) may be more suitable for the study of drought. For one drought event, the results of different drought indexes may vary, due to using different calculation methods. Currently, the Standardized Precipitation Index (SPI) $[9,10]$, the Standardized Precipitation Evapotranspiration Index (SPEI) [11-14], and the Palmer Drought Severity Index (PDSI) [15,16] have been widely used as popular drought indexes. Among them, the SPI is not only simple to calculate, but also can better reflect the drought conditions of different time scales. However, in terms of the global warming, the SPI only considers precipitation data and excludes other factors, such as temperature and evapotranspiration [17], which affects the further application of this method. Based on the SPI, the SPEI is proposed to include the effect of temperature changes on drought. The SPEI can be used to explore the correlation between the climate change and the rate of drought [18], and same as the SPI, it has the advantage of multiple time scales [13]. Therefore, the SPEI can better reflect the regional drought under the background of global warming, and has become an ideal index to evaluate drought under the background of global warming [1,19]. The disadvantage of SPEI is that estimation of evapotranspiration often requires a large amount of data, which is difficult to collect in many regions [20]. At present, the SPEI has been widely used in the study of drought mechanism, drought effect, and drought variation trend, across the world, including Asia, North America, Europe, Australia, and Africa [21-27]. The PDSI takes into account the effects of temperature and previous weather conditions on drought, and its physical mechanism is relatively clear and applicable to study the response of drought to the global warming [28]. However, due to the complexity of calculation and the high amount of required data, some parameters can only be estimated by experience, resulting in a great reduction in the calculation accuracy [29].

Xinjiang is a typical arid and semi-arid region, in the middle of Eurasian Plate. In terms of the influence of global warming and human activities, the drought disaster losses in Xinjiang are increasing [30]. Based on the PDSI [31], the SPI [32], the SPEI [20,32] and other drought indexes [33-35], many scholars have carried out studies on the drought characteristics of Xinjiang and local areas. Most drought indexes use precipitation to characterise the changes in drought, ignoring the effects of temperature rise on drought. However, in arid regions with large PET, the change of drought degree is mainly affected by the PET [32], therefore, for our study area, the drought index that considering the PET may be more suitable to study drought in Xinjiang, as an arid and semi-arid area. In some studies, while the appropriate indicators were considered, but a thorough analysis of the impact of climate warming on the drought situation was insufficient, and the effects of drought duration and the extent of the drought affected area on drought severity was not considered. Based on the comprehensive index of SPEI, the Regional Drought Severity (RDS), is proposed in this study, taking into account the drought duration and the extent of the drought affected area. It should be noted that this paper focuses on the effects of duration of the drought and the extent of the drought affected area, rather than proposing a new index with different meteorological factors. Because of this, we did not use any method to classify the RDS values for drought. Moreover, this method can also be applied to some other drought indexes and provide a new way to study drought for others due to its simple principle. Considering the SPEI as the main evaluation index, in combination with the RDS, the temporal-spatial distribution of drought in Xinjiang from 1960 to 2018 was comprehensively analysed. Furthermore, the influence of the climate warming on the drought situation in Xinjiang was analysed, by comparing 
the drought conditions before and after the climate warming and the changing trends of the SPEI and the SPI.

\section{Study Area}

The Xinjiang Uygur Autonomous Region $\left(73^{\circ} 40^{\prime}-96^{\circ} 18^{\prime} \mathrm{E}, 34^{\circ} 25^{\prime}-48^{\circ} 10^{\prime} \mathrm{N}\right)$ is a typical arid and semi-arid region, located in the middle of Eurasian Plate and north-west China. Desert oases and irrigation agriculture are the remarkable characteristics of Xinjiang. The total area of Xinjiang is about $1.60 \times 10^{4} \mathrm{~km}^{2}$, accounting for $1 / 6$ of the total land area of China. Xinjiang has a complex terrain, with an average altitude of about $1000 \mathrm{~m}$. From the north to the south, the Altai Mountains, Junggar Basin, Tianshan, Tarim Basin, and Kunlun Mountains are the main geographical features in the area. The barrier of high mountains makes it difficult for the sea currents to reach to the area, and the widely developed inland rivers became the unique mountain-oasis-desert system (MODS), in the global arid region [36]. The average annual precipitation in Xinjiang from 1960 to 2018 was $154.8 \mathrm{~mm}$, with an average annual temperature of $9.2^{\circ} \mathrm{C}$. Xinjiang has limited fertile agricultural land and most areas are including the Gobi desert and grassland. Its unique climatic conditions are suitable for the growth of cotton, and for the period between 2017 and 2018, cotton output was accounted for more than $70 \%$ of China's total output. At the same time, the large area of the grassland have promoted the booming development of the animal husbandry, making Xinjiang the second largest stockbreeding province in China, after Inner Mongolia.

However, the shortage of water resources, caused by drought, is the key factor which affects the ecological balance and restricts the sustainable development of economy and the construction of ecological civilization in Xinjiang. Moreover, the frequency and intensity of extreme drought events in the north-west China are increasing, as a result of the climate warming, and the impacts of extreme drought events are increasing, significantly [37]. As an important industry, supporting economic and social development of Xinjiang, the agriculture and animal husbandry will be affected by drought, which will then directly affect the social and economic development in Xinjiang. Therefore, it is of practical significance to explore the characteristics of drought change in Xinjiang.

\section{Materials and Methods}

\subsection{Data Sources}

In our study, the monthly temperature and precipitation data of 106 meteorological observation stations in Xinjiang were selected to obtain data from 1960 to 2018, provided by China Meteorological Data Sharing Service System. Before data processing, firstly, the missing data were corrected and interpolated, and stations with more missing measurements in the temperature and precipitation series were eliminated. Moreover, the stations with less missing data were interpolated, and the missing values were interpolated by cubic spline function. Consequently, 95 stations with complete and continuous sequence were obtained, as shown in Figure 1. There are 134,520 data of monthly precipitation and monthly temperature from 95 stations. The missing data are 564 and the missing rate is only $0.42 \%$.

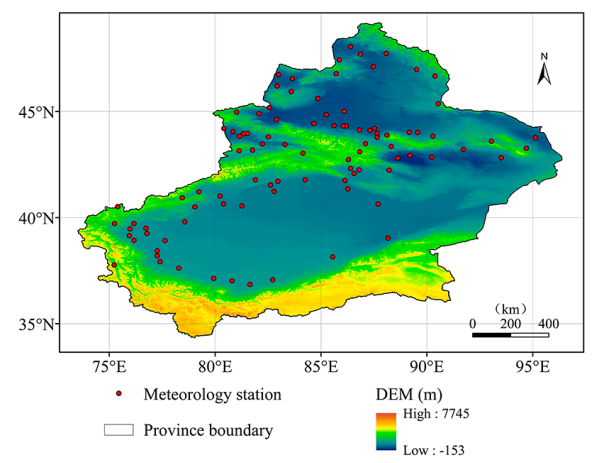

Figure 1. Elevation map and distribution of the meteorological observation stations, in Xinjiang. 


\subsection{SPEI and Its Calculating Methods}

According to the monthly temperature and precipitation data of 95 stations in Xinjiang, the SPEI at different time scales were calculated for each site, and the SPEI values of the whole Xinjiang were obtained, using the Thiessen polygon method. Based on the SPEI index at different time scales (SPEI-1, SPEI-3, SPEI-6, SPEI-12), the evolution characteristics of the monthly, annual, and seasonal droughts, as well as drought during the growing season were analysed. The droughts of each month were characterised by the SPEI-1, covering the period of January to December, the SPEI-3, covering the months of May, August, November, and February, which represents the droughts in spring, summer, autumn, and winter, respectively. Moreover, the SPEI-6 in August can be used to characterise droughts during the plant growing season, and SPEI-12 in December can be used to characterise the annual droughts. If the time-scale is not specified in the following text, the SPEI is the December value of the SPEI-12.

The SPEI is the index, after normalizing the cumulative probability of the difference series of precipitation and potential evapotranspiration. Firstly, the Thornthwaite method was used to calculate the potential evapotranspiration, then the difference between the monthly precipitation and the evapotranspiration was calculated, and the accumulation sequence of water deficit, during different time scales, was established. Since there might be negative values in the original data sequence, the three-parameter Log-logistic probability distribution was used to standardise the cumulative probability density, consequently, the SPEI value was calculated. The calculation process is as follow $[1,38,39]$.

Firstly, the Thornthwaite method was used to calculate the potential evapotranspiration (PET):

$$
\begin{gathered}
\text { PET }=16 \times\left(\frac{N}{12}\right) \times\left(\frac{m}{30}\right) \times\left(\frac{10 T_{i}}{H}\right)^{k} \\
H=\sum_{i=1}^{12} H_{i}=\sum_{i=1}^{12}\left(\frac{T_{i}}{5}\right) \\
k=6.75 \times 10^{-7} H^{3}-7.71 \times 10^{-5} H^{2}+1.79 \times 10^{-2} H+0.492
\end{gathered}
$$

where, PET is the potential evapotranspiration, $T_{i}$ is the monthly average temperature, $N$ is the average daily sunshine duration of each month, $m$ is the number of days in a month, $H$ is the annual heat index, and $k$ is the coefficient determined by the annual heat index.

Then, the difference between monthly precipitation and evapotranspiration was calculated, as follows:

$$
D_{i}=P_{i}-\mathrm{PET}_{i}
$$

where, $D_{i}$ is the difference between the precipitation and the evapotranspiration, $P_{i}$ is the monthly precipitation, and the $\mathrm{PET}_{\mathrm{i}}$ represents the monthly evapotranspiration.

Subsequently, the difference value of precipitation and evapotranspiration at different time scales was calculated, as follows:

$$
D_{n}^{k}=\sum_{i=0}^{k-1}\left(P_{n-i}-P E T_{n-i}\right), \quad n \geq k
$$

where, $k$ is the time scale (i.e., month), and $n$ is the calculation frequency.

Then, three-parameter Log-logistic probability distribution was used to normalize $D$ data sequence to calculate the SPEI, corresponding to each value:

$$
F(x)=\left[1+\left(\frac{\alpha}{x-\gamma}\right)^{\beta}\right]^{-1}
$$


The calculation process of each parameter is as follows:

$$
\begin{gathered}
\alpha=\frac{\left(\omega_{0}-2 \omega_{1}\right) \beta}{\Gamma(1+1 / \beta) \Gamma(1-1 / \beta)} \\
\beta=\frac{2 \omega_{1}-\omega_{0}}{6 \omega_{1}-\omega_{0}-6 \omega_{2}} \\
\gamma=\omega_{0}-\alpha \Gamma(1+1 / \beta) \Gamma(1-1 / \beta)
\end{gathered}
$$

where, $\Gamma$ is factorial function, and $\omega_{0}, \omega_{1}, \omega_{2}$ are the probability weighted moment of $D$ data series:

$$
\begin{gathered}
\omega_{s}=\frac{1}{N} \sum_{i=1}^{N}\left(1-F_{i}\right) D_{i} \\
F_{i}=\frac{i-0.35}{N}
\end{gathered}
$$

where, $N$ is the number of months in the calculation.

Ultimately, the cumulative probability density was standardized:

$$
P=1-F(x)
$$

when the cumulative probability $P \leq 0.5$ :

$$
\begin{gathered}
\omega=\sqrt{-2 \ln (P)} \\
\text { SPEI }=\omega-\frac{c_{0}+c_{1} \omega+c_{2} \omega^{2}}{1+d_{1} \omega+d_{2} \omega^{2}+d_{3} \omega^{3}}
\end{gathered}
$$

where, the constants $c_{0}, c_{1}, c_{2}, d_{1}, d_{2}, d_{3}$ are:

$$
\begin{aligned}
& c_{0}=2.515517, \\
& c_{1}=0.802853, \\
& c_{2}=0.010328, \\
& d_{1}=1.432788, \\
& d_{2}=0.189269, \\
& d_{3}=0.001308 .
\end{aligned}
$$

Finally, the drought classification was graded, according to the SPEI value (Table 1).

Table 1. Drought classification, based on the SPEI value.

\begin{tabular}{ccccc}
\hline No Drought & Mild Drought & Moderate Drought & Severe Drought & Extreme Drought \\
\hline$-0.5<\mathrm{SPEI}$ & $-1<\mathrm{SPEI} \leq-0.5$ & $-1.5<\mathrm{SPEI} \leq-1$ & $-2<\mathrm{SPEI} \leq-1.5$ & $\mathrm{SPEI} \leq-2$ \\
\hline
\end{tabular}

\subsection{SPI and Its Calculation Method}

The SPI is an indicator of the precipitation probability in a certain period of time, which is suitable for monitoring and evaluating droughts over the monthly-scale, under the local climate conditions [40]. In comparison with the SPEI, the calculation of SPI exclude the effect of evapotranspiration. In our study, the changing trends of the annual SPI and SPEI were compared, in order to analyse the influence of climate warming on droughts.

The SPI uses $\Gamma$ distribution probability to describe changes in precipitation. The precipitation of the skewed probability distribution was normalised, and distribution of the standardised precipitation 
accumulation frequency was used to classify the drought degrees, in the study area. The calculation formula of the SPI is as follows $[9,41]$ :

$$
\begin{gathered}
\mathrm{SPI}=S \frac{t-\left(c_{2} t+c_{1}\right) t+c_{0}}{\left(\left(d_{3} t+d_{2}\right) t+d_{1}\right) t+1.0} \\
t=\sqrt{\ln \frac{1}{G(x)^{2}}}
\end{gathered}
$$

where, $G(x)$ is the precipitation distribution probability, related to the $\Gamma$ function, $x$ is the sample value of precipitation, $S$ is the positive and negative coefficient of probability density, and the values of the constants $c_{0}, c_{1}, c_{2}, d_{1}, d_{2}, d_{3}$ are the same as described in the SPEI calculation. When $G(x)>0.5, G(x)=$ $1.0-G(x), S=1$. When $G(x) \leq 0.5, S=-1 . G(x)$ is obtained by the following $\Gamma$ distribution function probability density integral equation:

$$
G(x)=\frac{1}{\beta^{\gamma} \Gamma(\gamma)} \int_{0}^{x} x^{\gamma-1} e^{-x / \beta} d x, x>0
$$

where, $\gamma$ is the shape parameter of the $\Gamma$ distribution function, and $\beta$ is the scale parameter of the $\Gamma$ distribution function. The calculation formula is as follows:

$$
\begin{gathered}
\gamma=\frac{1}{4 A}\left(1+\sqrt{1+\frac{4 A}{3}}\right) \\
A=\ln (\bar{x})-\frac{\sum \ln x}{n} \\
\beta=\frac{\bar{x}}{\gamma}
\end{gathered}
$$

where, $n$ is the sample size of precipitation.

\subsection{RDS (Region Drought Severity) and Its Calculating Method}

In terms of climatic conditions, the SPEI and the SPI can reflect the drought degree, in different time scales. However, taking the annual-scale as example, the SPEI and the SPI can only reflect the drought conditions, reflected by the climatic conditions of that year, while the effects of successive droughts and drought range are not taken into account. For instance, the third consecutive year of moderate drought in a region produces cumulative effects, due to occurrence of continuous drought in the region. Therefore, the damage, caused by the moderate drought in the third continuous year might be similar to the severe drought year after a humid year. In terms of drought range, for the same drought degree, the increased drought range is more harmful to the economy and society. The SPI and SPEI can only reflect the drought degree, determined by the climate conditions of that year. Therefore, without considering the cumulative effects of drought and the influence range, the actual severity of the drought in that specific year cannot be reflected.

In order to reflect the changing characteristics of drought severity, in our study, based on the SPEI, a comprehensive index RDS- Regional Drought Severity was proposed, taking into account the effect of the continuous drought from the perspective of time and the extent of the drought affected area from the perspective of space. The calculation formula is as follows:

$$
\operatorname{RDS}= \begin{cases}\text { SPEI }-\mathrm{t} \times \frac{a_{+}}{\bar{a}_{+}} \times \frac{S_{+}}{\overline{\bar{S}}_{+}}, & \text {SPEI }-\mathrm{t}>0 \\ \mathrm{SPEI}-\mathrm{t} \times \frac{a_{-}}{\bar{a}_{-}} \times \frac{S_{-}}{\bar{S}_{-}}, & \text {SPEI }-\mathrm{t}<0\end{cases}
$$


where, the SPEI-t is the SPEI value on the $t$ time scale. $a_{+}\left(a_{-}\right)$is the cumulative value of SPEI for consecutive non-arid (arid) years. That is, if one year is the beginning of non-drought (drought), then the $a_{+}\left(a_{-}\right)$of this year is the SPEI value. If the subsequent year is the consecutive non-arid (arid) year with that year, then the value of $a_{+}\left(a_{-}\right)$in subsequent year is the sum of the SPEI values of all years from the beginning year of non-arid (arid) to the year. $\bar{a}_{+}\left(\bar{a}_{-}\right)$is the mean value of $a_{+}\left(a_{-}\right)$over the years. $S_{+}\left(S_{-}\right)$is the proportion of non-arid (arid) area, while $\bar{S}_{+}\left(\bar{S}_{-}\right)$is the mean value of $S_{+}\left(S_{-}\right)$, over the years.

\subsection{Mann-Kendall-Sneyers Test}

Mann-Kendall-Sneyers test (M-K-S test) is an effective tool to extract the sequence change trend and has been widely used in the analysis of climate parameters and hydrological sequences [42]. The M-K-S test is famous for its wide range of applications, little human influence, and high quantification. The method is illustrated in Equation (23), and for a time series with $n$ sample sizes, an order sequence is constructed, as follows:

$$
\begin{aligned}
& u_{k}=\sum_{i=1}^{k} r_{i}, \quad(2 \leq k \leq n), \\
& r_{i}=\left\{\begin{array}{ll}
1 & x_{i}>x_{j} \\
0 & \text { else }
\end{array} \quad j=1,2, \ldots, i .\right.
\end{aligned}
$$

where, the order sequence $u_{k}$ is the cumulative number of values at time $i$ greater than time $j$. Assuming the time series is random and independent, the statistic $U F_{k}$ can be defined, as follows:

$$
U F_{k}=\frac{u_{k}-E\left(u_{k}\right)}{\sqrt{\operatorname{Var}\left(u_{k}\right)}}, \quad k=1,2, \ldots, n .
$$

where, $U F_{1}=0, E\left(u_{k}\right)$ and $\operatorname{Var}\left(u_{k}\right)$ are the average value and variance of the cumulative number $u_{k}$. When $x_{1}, x_{2}, \ldots, x_{n}$ are independent and has the same continuous distribution, their values can be calculated by the following formula:

$$
\begin{aligned}
& E\left(u_{k}\right)=\frac{k(k-1)}{4}, \\
& \operatorname{Var}\left(u_{k}\right)=\frac{k(k-1)(2 k+5)}{72}, \quad(2 \leq k \leq n)
\end{aligned}
$$

The antitone sequence $U B_{k}$ curve was drawn in the same way. Where, $x$ can be reversed according to time series to get $x_{n}, x_{n-1}, \ldots, x_{1}$, and the above process is repeated. Meanwhile, making $U B_{k}=-U F_{k}, \quad k=n, n-1, \ldots, 1$, then $U B_{1}=0$.

The curve of $U F_{k}$ and $U B_{k}$ are illustrated and corresponding critical lines are plotted, according to different significance levels $\alpha$. When the curve of $U F_{k}$ exceeds the critical line, it indicates a significant upward or downward trend. If there are intersection points between the $U F_{k}$ and the $U B_{k}$, with the intersection points between the critical lines, then the time at the intersection is when the mutation starts.

\section{Result and Discussion}

\subsection{Inter-Annual Variation Characteristics of SPEI and RDS}

Figure 2a shows the inter-annual variation of the annual SPEI. As displayed in Figure 2a, the SPEI value showed a significant drop, with 1997 as the dividing line. The SPEI values were positive for most of the years between 1960 and 1996, and only the SPEI values in 1978 and 1980 were less than -0.5 , suggesting moderate drought and mild drought, respectively.

Since 1997, the SPEI values have been almost always negative, with the only positive values, observed in 2003 and 2010. As it can be seen from the SPEI cumulative curve, the cumulative value 
of SPEI was on the rise before 1997 and peaked at 13.43 in 1996, followed by an overall declining tendency. The above results indicated that the frequency of annual drought events in Xinjiang has significantly increased since 1997, which was consistent with the results of Yao et al. [32] that the droughts occurred more frequently since 1997, according to their analysis on the Xinjiang droughts, using the SPEI. Figure $2 b$ demonstrates the inter-annual variation of the annual RDS. Changes in the RDS values were generally consistent with the changes in the SPEI values. The RDS values in 2008 and 2009 were particularly low, suggesting the most severe economic and social impacts of the droughts in 2008 and 2009, due to large arid areas and successive droughts. Meanwhile, the cumulative value of RDS reached the minimum value of -0.72 in 2018, while the cumulative value of SPEI stayed always positive. This indicated that the drought results, obtained by the RDS were more severe than those, obtained by the SPEI, when considering the extent of the drought affected area and successive droughts.

As a large province of agriculture and animal husbandry, the economic and social development of Xinjiang is dependent on the growth of crops and grasslands. Therefore, the changes of SPEI and RDS value over the years in plant growing season were analysed in our study. Based on the overall tendency of SPEI values in plant growing season in Figure 3a, the drought characteristics during the plant growing season were similar to the annual drought characteristics. During 1960-1996, a few drought events existed, however, since 1997, drought began to occur more frequently, resulting in occurrence of 14 drought events over a period of 22 years, from 1997 to 2018 (SPEI $<-0.5$ ). As displayed in Figure 3b, in 2008 and 2009, the RDS values of plant growing season were especially low, which were similar to the annual RDS values. In addition to these two years, the RDS values of plant growing season in the last four years were also low. It is mainly due to the low SPEI values in these years (Figure 3a), which was then affected by continuous drought (eight consecutive years of drought for the period of 2011 to 2018) and the large arid area, which greatly exacerbated the drought severity.

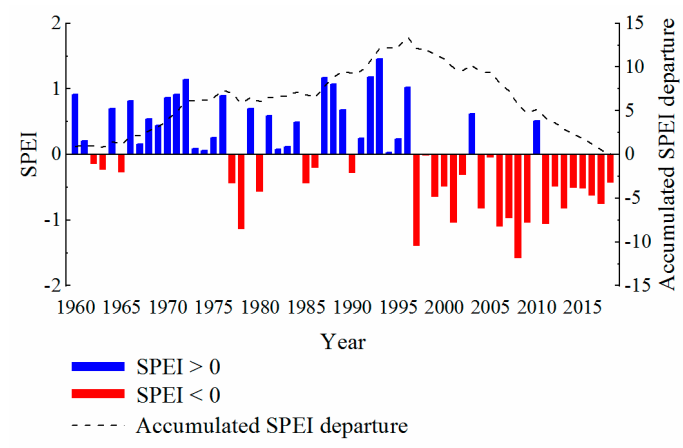

(a)

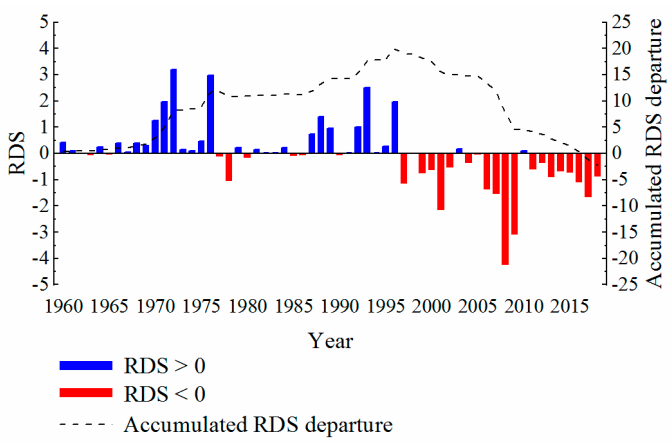

(b)

Figure 2. Change characteristics of the annual SPEI values (a) and the annual RDS values (b), over the years.

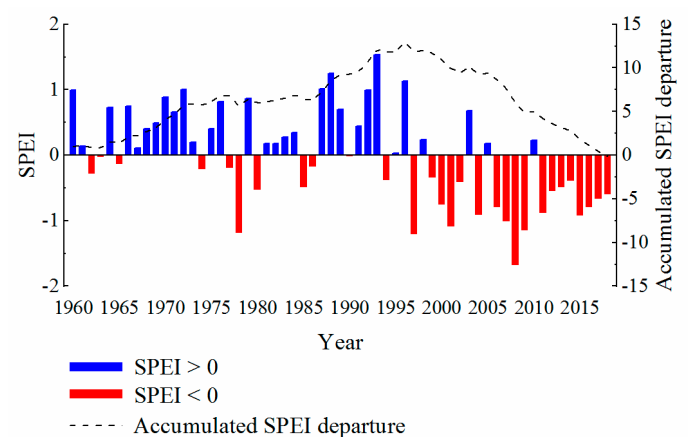

(a)

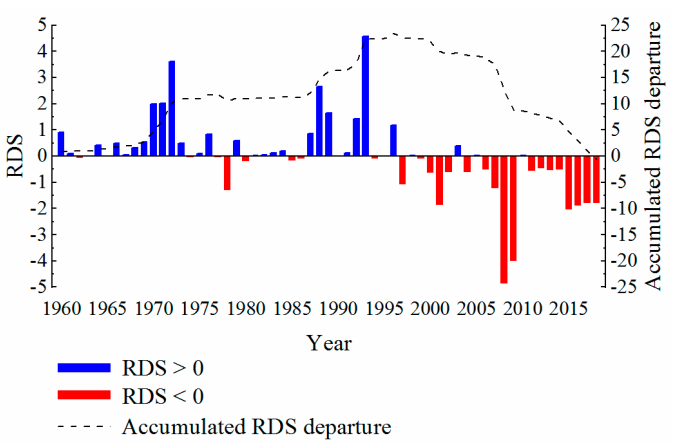

(b)

Figure 3. Change characteristics of the SPEI values (a) and the RDS values (b), over the years in plant growing season. 
To further analyse the drought characteristics in Xinjiang, the SPEI and RDS values of four seasons in Xinjiang were analysed, as presented in Figure 4. Overall, the change tendencies of SPEI values in spring, summer, and autumn were similar to that of the annual and plant growing season. Before the 1990s, the wet climate was dominant in the area, however, and after the 1990s, the dry climate became more dominant. In contrary to the other seasons, winter showed a phenomenon of having a period of drought, first, followed by wet climate. From the cumulative curves of SPEI and RDS, the same tendency was observed in the final cumulative values of SPEI and RDS in spring, while the final cumulative values of RDS in summer were significantly higher than that of the SPEI. This indicated that the occurrence frequency of large area drought events or continuous drought events was lower during the summer, which reduced the drought severity. The final cumulative values of RDS during the autumn and winter were slightly less, in comparison with the SPEI values, which was similar to the difference between the cumulative values of the annual RDS value and SPEI values. Based on the differences in cumulative values of SPEI and RDS, it can be interpreted that the severity of drought in summer and winter, obtained by the RDS was lighter than that of obtained by the SPEI, while the severity of drought in autumn was slightly heavier than that of obtained by the SPEI.
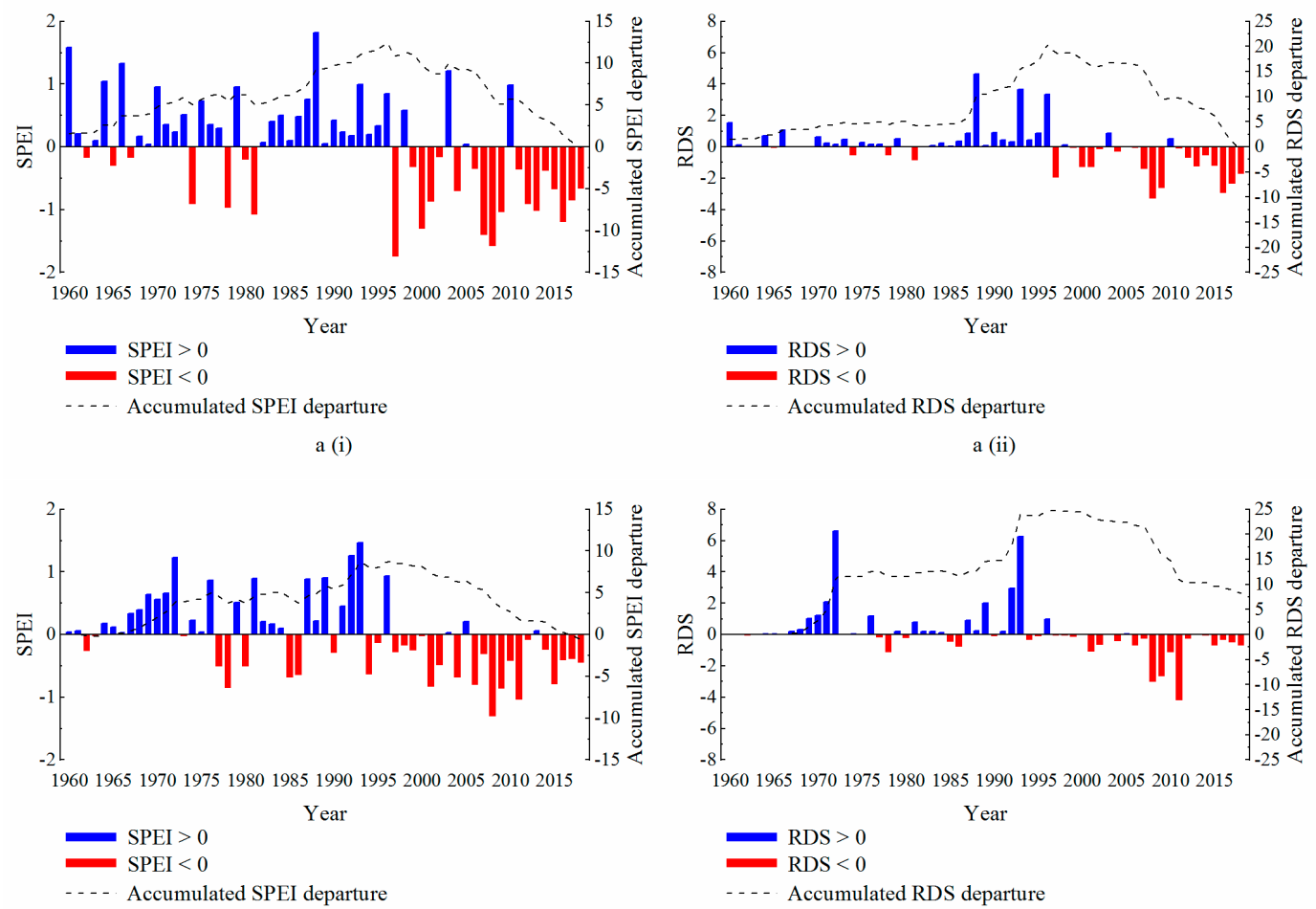

b (i)

b (ii)
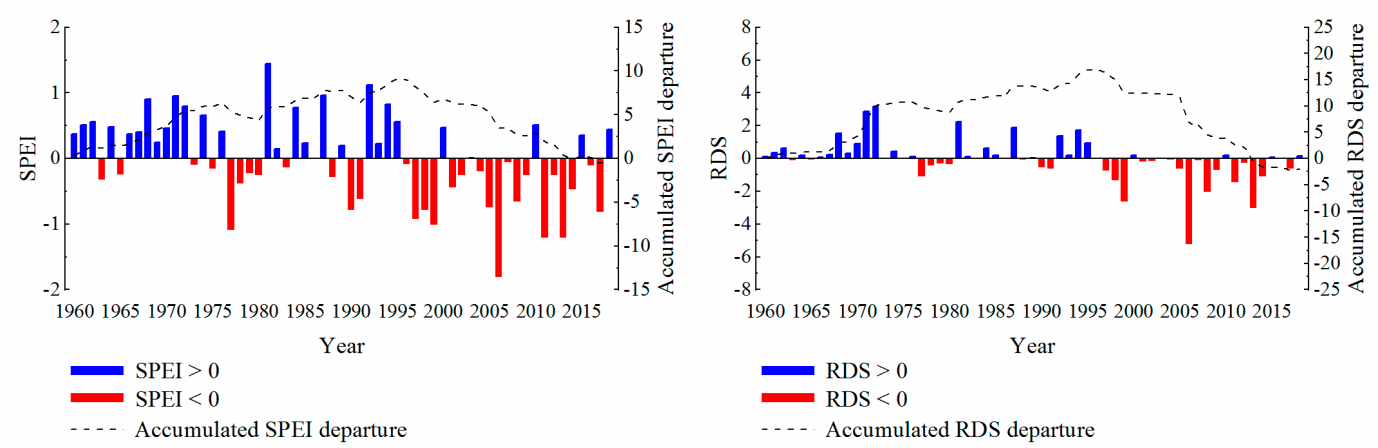

c (i)

c (ii)

Figure 4. Cont. 

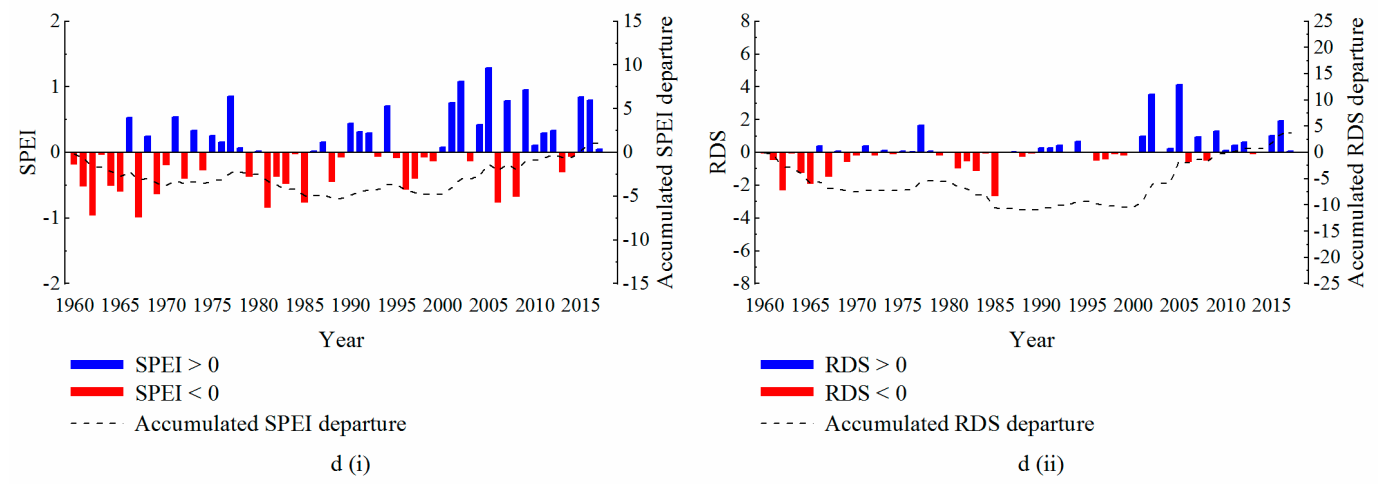

Figure 4. The changes in the SPEI (i) and RDS (ii) values, over the years in spring (a), summer (b), autumn (c), and winter (d).

\subsection{Change Characteristics of Arid Area}

Figure 5 shows the changes in percentage of arid area across the study area, over the years. From the change of the five-year moving average of the arid area proportion, it can be observed that a fluctuating rising tendency was observed in the arid area, as a whole. Since 1997, the arid area has changed, significantly. In 1996, the arid area accounted for a relatively small value of $7.28 \%$. Subsequently, in 1997, the arid area expanded rapidly, reaching up to $87.98 \%$. After that, the arid area fluctuated up and down, but the arid area had increased significantly in most of the years, compared to the previous years. Before 1996, there were fewer years when the drought area exceeded 50\%, however, after 1997, the frequency of large-scale drought events increased, significantly. In 15 out of 22 years, the drought area exceeded $50 \%$, in which, 6 years experienced a drought, exceeded $70 \%$. In 2008 , the drought area was the largest, accounting for $93.90 \%$.

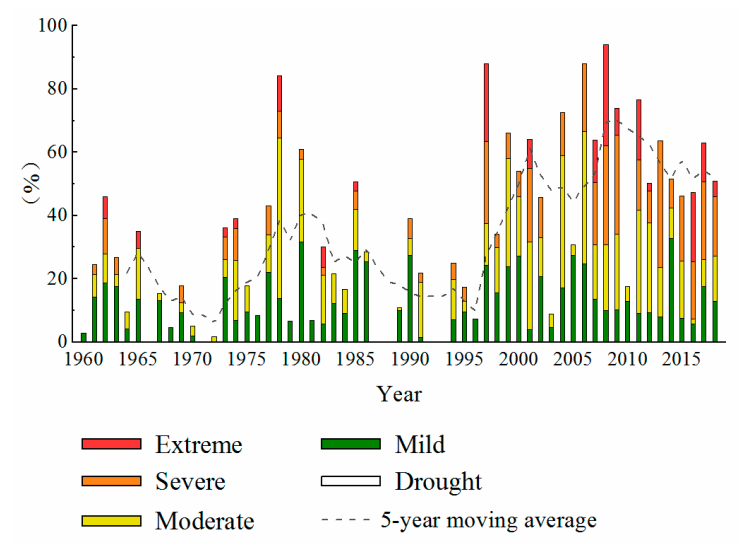

Figure 5. The changes of arid area ratio over the years.

In terms of the drought types, from 1960 to 1996, the drought in the study area was mainly composed of mild drought and moderate drought, with a small proportion of severe and extreme droughts. From 1997 to 2018, the arid area expanded greatly, and moderate and severe droughts became more dominant. Meanwhile, the proportion of extreme drought was still small, with a reduction in the proportion of mild drought. However, due to the expansion of the total arid area, the actual arid area of each drought grade had a certain increase, overall.

In general, the change characteristics of arid area are consistent with the change characteristics of the drought situations which were analysed previously, accompanied with 1997 as the turning point. The drought quickly became severe, after 1997. On the one hand, the arid area began to expand more rapidly, on the other hand, the drought intensified, changing from a predominantly mild and moderate drought to a moderate and severe drought. 
The changes of arid area ratio over the years in plant growing season and four seasons in study area are presented in Figures 6 and $7 a-d$, respectively. Among them, the variation of arid area in the plant growing season was basically consistent with the variation tendency of the annual arid area, while the variation of arid area in each season has its own characteristics. The arid area during the spring, summer, and autumn seasons showed an overall increasing tendency, which was mainly manifested by the expansion of severe and extreme drought areas. The arid area in the winter showed a declining tendency, while, all drought grades presented a decreasing tendency, as well. Furthermore, the characteristics of drought were compared during each of the four seasons. From 1997 to 2018, frequent severe drought events were observed during the spring. In 1997, the arid area reached the maximum value of $94.66 \%$, and from 2007 to 2009 , the arid area exceeded $75 \%$ for three consecutive years. In the 1990s, the summer and autumn showed the characteristics of regional drought for several consecutive years. A regional drought event occurred during the summer of every year, for 25 consecutive years (i.e., 1994 to 2018), and for the 26 consecutive years of autumn (i.e., 1993 to 2018). The winters were characterised by regional drought, occurring almost every year. During 1960-2018, only the arid area in 2005 was 0 . However, the severity of winter drought was low and it was mainly included the mild drought, with a few areas, where severe drought and extreme drought occurred.

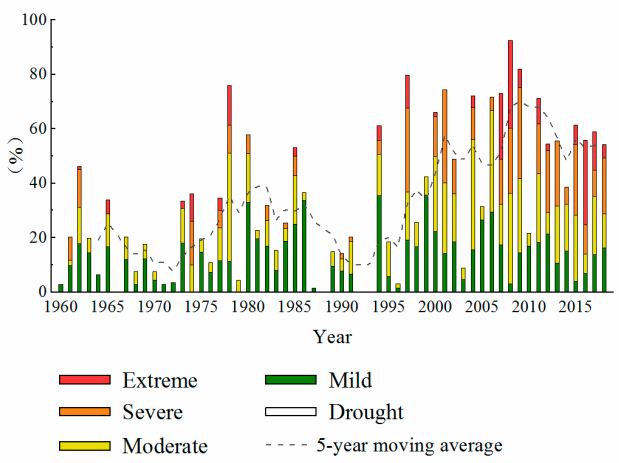

Figure 6. The changes of arid area ratio over the years, in plant growing season.
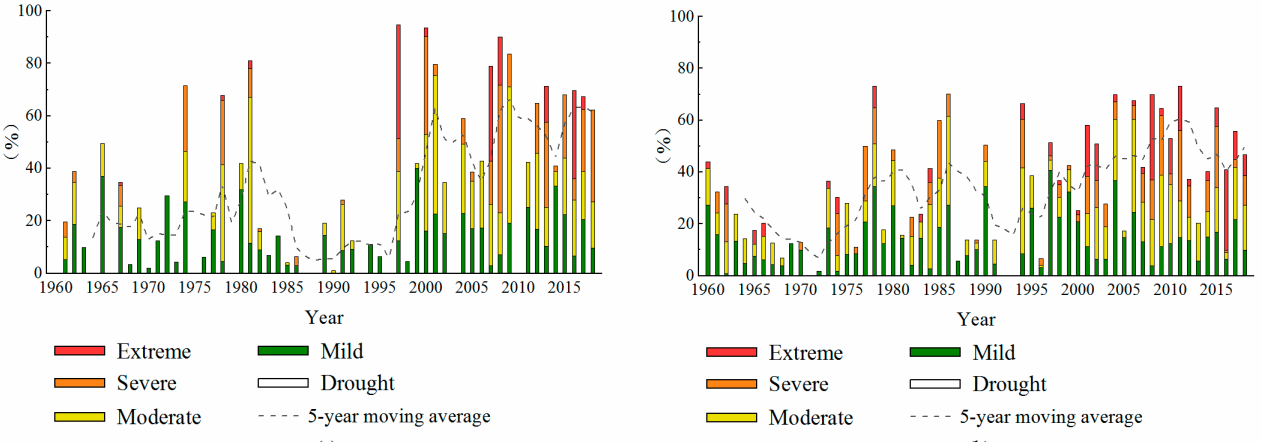

(a)
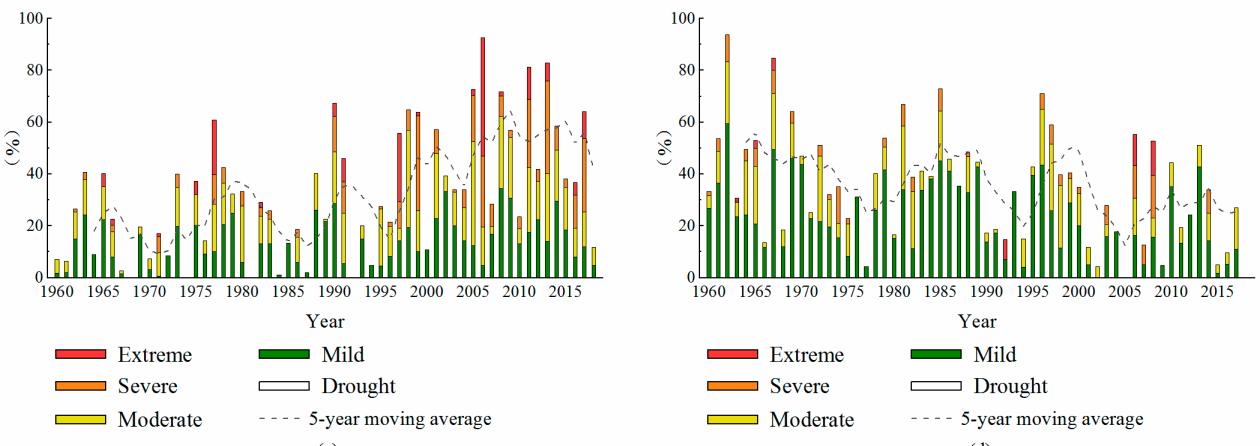

(c)

(d)

Figure 7. The changes of arid area ratio over the years, in spring (a), summer (b), autumn (c) and winter (d). 


\subsection{The Characteristics of Intra-Annual Drought}

Monthly SPEI values were used to analyse the annual distribution of drought in Xinjiang (Figure 8). As it can be seen from the figure, before 1978, the frequency of drought was relatively low, also, the drought types were all including the mild or the moderate droughts, and dominated by the mild drought. Furthermore, droughts occurred more frequently during the January and December. Since 1978, droughts began to shift throughout the year, gradually concentrating in March-November.

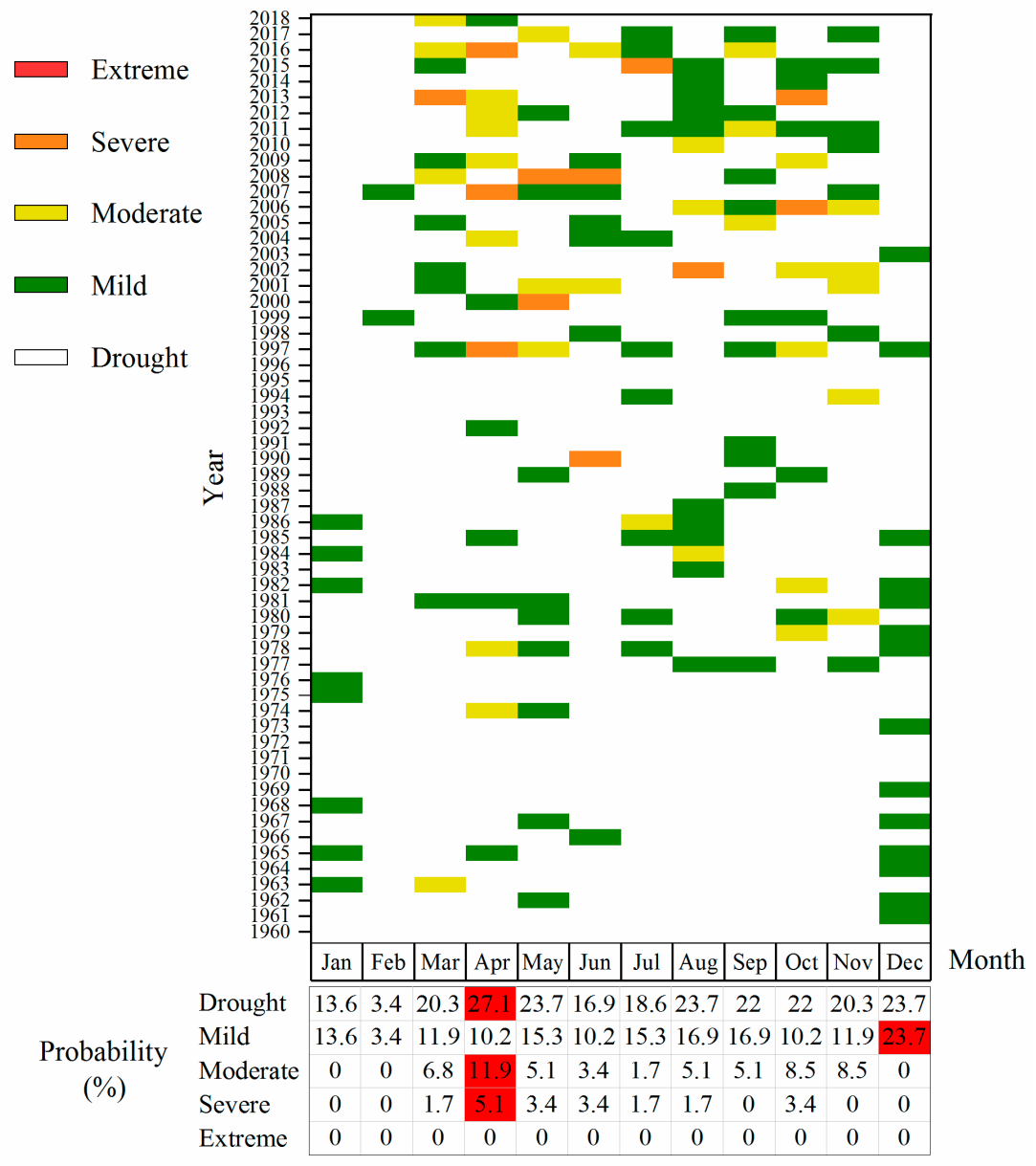

Figure 8. Distribution and occurrence frequency of intra-annual drought.

During this period, the drought type was mainly dominated by the mild and moderate drought, with few severe droughts. In terms of the drought frequency, the highest frequency of drought occurred in April, at 27.1\%, and its lowest frequency occurred in February, at only 3.4\%. From the perspective of drought type, December was the month with the highest frequency of mild droughts, at $23.7 \%$. In addition, only the mild droughts occurred during the three months of winter (December-February). April was identified as the month with the highest frequency of moderate and severe drought, when the frequency of moderate and severe drought in April was 11.9\% and 5.1\%, respectively. Therefore, corresponding measures should be made according to the drought situations during different months, in order to ensure that agricultural and animal husbandry production have not been affected by drought. For instance, during the winter, it is enough to take required approach to prevent the mild drought. While, considering occurrence of severe droughts, with higher frequency during April, it is necessary to make additional plan to prepare for the severe droughts to come. 


\subsection{M-K-S Test}

Based on previous analysis of the changes of SPEI values, during different time scales over the years, our results suggested that the SPEI values around 1997 have undergone great changes, therefore, the mutation test of the SPEI value was performed, using the M-K-S test (Figure 9). As displayed in Figure 9, within the threshold of significance level 0.01 , the intersection of UF and UB was located near to the year 1997, so the SPEI value mutation occurred near 1997.

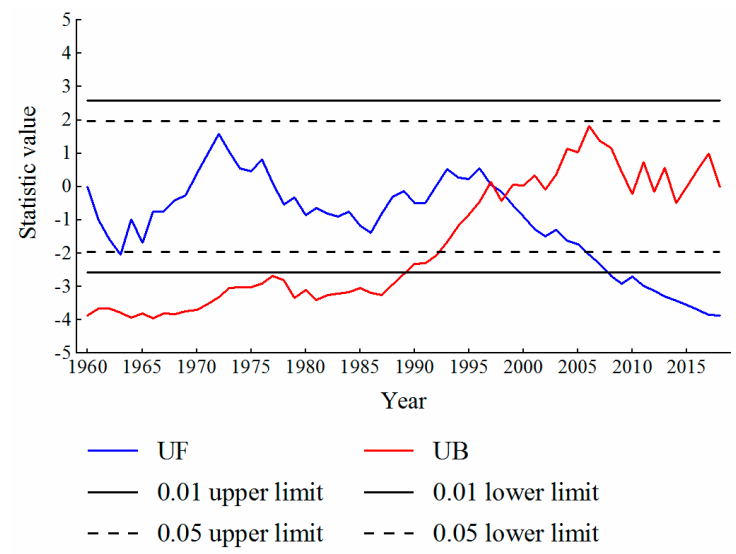

Figure 9. M-K-S test results of the annual SPEI.

To further understand the reason for mutation, the M-K-S test was conducted for the two main factors, affecting the SPEI value, including precipitation and temperature. Figure 10 shows the M-K-S test results of the annual mean precipitation and the annual mean temperature in Xinjiang. As it can be seen from the figure, the precipitation and temperature in Xinjiang had a sudden change in 1995 and 1993, respectively, with an obvious increasing trend since 2003 and 1997, respectively (within the threshold of significance level 0.01). In view of the increase of the UF curve, the increase of temperature was obviously larger, in comparison with the precipitation. Therefore, the effect of excessively rapid temperature increase on the SPEI value could exceed the impact of precipitation growth, which led to the rapid decline of the SPEI value.

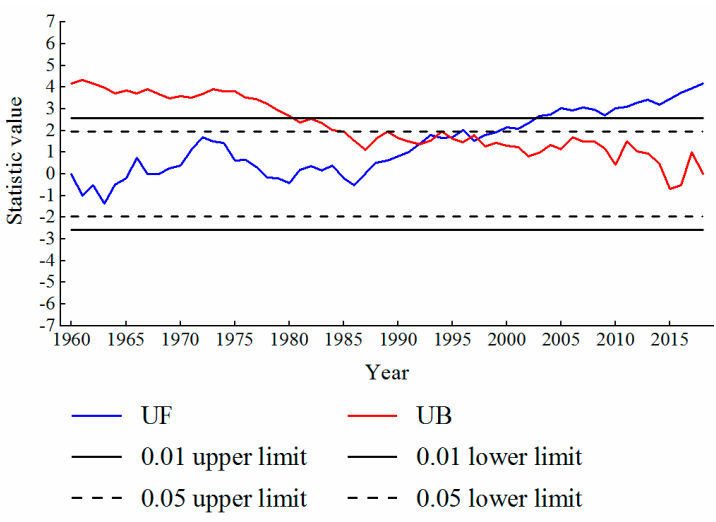

(a)

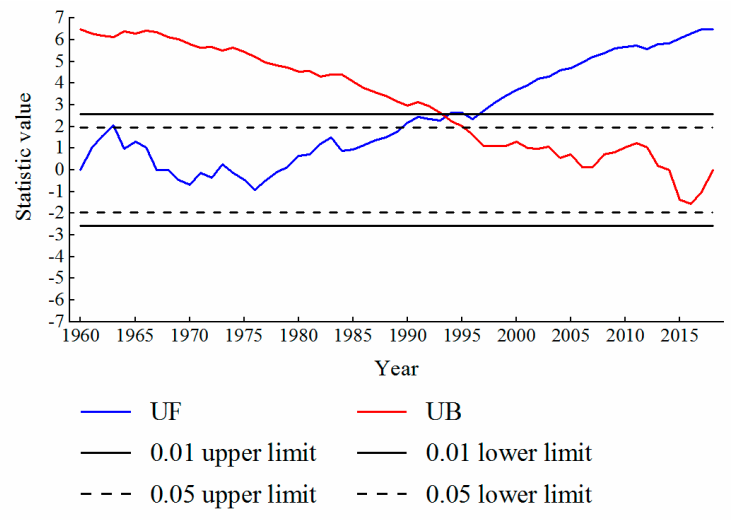

(b)

Figure 10. M-K-S test results of the annual mean precipitation (a) and annual mean temperature (b).

\subsection{Changes of Occurrence Frequency and Duration of Drought}

In order to explore the drought characteristics before and after the meteorological change, the occurrence frequency of drought and the longest drought duration before and after the meteorological change were compared and analysed (Table 2). The frequency of drought from 1997 to 2018 was $59.09 \%$, which was 10.9 times the occurrence of drought before the meteorological change (i.e., 5.41\%). 
The occurrence frequency of the mild and moderate drought was about 10 times higher, compared to the period before the meteorological change. However, no severe drought occurred before the meteorological change, while, the occurrence frequency of severe drought after the meteorological change was $4.55 \%$. In terms of drought duration, the longest drought in period between 1960 and 1996 was 13 months, while the number of month increased to 44 months, for the period after the meteorological change (i.e., 3.38 times higher). Moreover, the longest duration of mild drought was 1.43 times and the moderate drought was 0.82 times higher, in comparison with the period before the meteorological change. No severe drought occurred during the period before the meteorological change, and the maximum duration of severe drought after the meteorological change was 5 months.

Table 2. Comparison between the occurrence frequency of drought and longest drought duration for the periods of 1960-1996 and 1997-2018.

\begin{tabular}{cccc}
\hline Item & Degrees & $\mathbf{1 9 6 0 - 1 9 9 6}$ & $\mathbf{1 9 9 7 - 2 0 1 8}$ \\
\hline & Drought & 5.41 & 59.09 \\
Occurence rate (\%) & Mild & 2.70 & 31.82 \\
& Moderate & 2.70 & 22.73 \\
& Severe & 0 & 4.55 \\
& Extreme & 0 & 0 \\
\hline \multirow{3}{*}{ Longest duration } & Drought & 13 & 44 \\
(number of months) & Mild & 7 & 10 \\
& Moderate & 11 & 9 \\
& Severe & 0 & 5 \\
& Extreme & 0 & 0 \\
\hline
\end{tabular}

\subsection{Effects of Climate Warming on Spatial Distribution of Drought}

Based on the above analysis, the increase in temperature can be identified as one of the causes for increasing the frequency of drought. To further analyse the influence of climate warming on the spatial distribution of drought in Xinjiang, the variation trends of SPEI values and SPI values at various stations, were calculated for the different periods. Furthermore, the inverse distance weighting interpolation method was used to obtain the variation trend in the whole research area (Figure 11). Since the meteorological change occurred in the 1990s, the entire investigation period can be divided into two periods of 1960-1990 and 1991-2018.

From 1960 to 1990, a declining trend of SPEI values was observed in most areas, suggesting a drier climate, with a slow declining rate. In most areas, the decline rate was (0-0.2)/10a. Meanwhile, the SPEI value increased in the parts of western Xinjiang and small areas of eastern Xinjiang, suggesting occurrence of a wetter climate. The situation of SPI in the same period was as follows: the SPI value in most regions showed an upward trend, and the rising rate was mostly $(0-0.2) / 10 \mathrm{a}$. Only the western region and a small part of central regions showed a downward trend. During 1991 to 2018, the SPEI value began to decline, rapidly, and covered a wide range. The SPEI values in more than half of the study area from the south-east to the north-west decreased rapidly, with a rate of more than 0.4/10a. Only few areas in the north-western Xinjiang showed a rise in the SPEI values. However, the spatial variation of SPI value was far different from that of SPEI value. The SPI values in most areas still showed an upward trend, and the upward rate in the north-west was significantly accelerated, reaching up to (0.2-0.4)/10a, in most areas, even exceeding $0.4 / 10 a$, in a small area.

In consideration of the fact that the decline rate of the SPEI is faster than that of the SPI, it is possible that rising temperatures may indeed have contributed to an increased rate of drought. From the spatial distribution of SPEI value, an obvious increasing drought trend was observed in the south-east of the study area, after the meteorological change. The causes can be analysed as follows: (1) From the change of SPI value, it can be seen that the north-west region received more precipitation, compared to the south-east, which alleviated the aggravation of drought. (2) In the south-east, due to the lack of precipitation and temperature rise, the drought seriously intensified. 

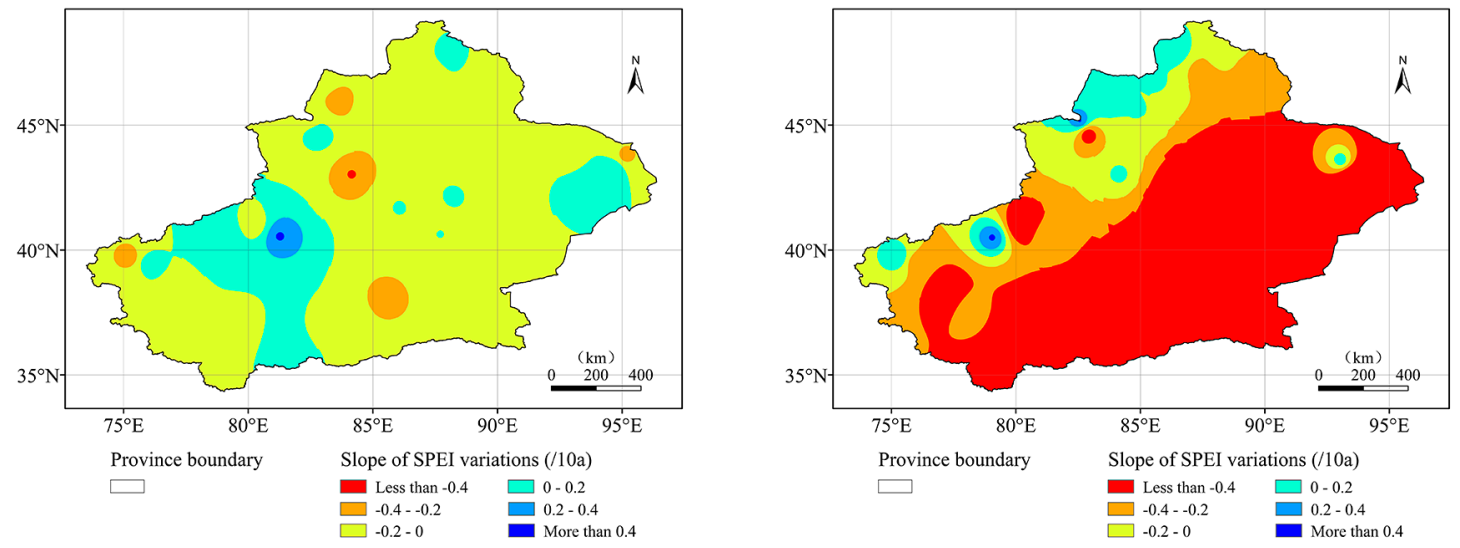

(a) SPEI during 1960-1990 (left hand side) and 1991-2018 (right hand side)
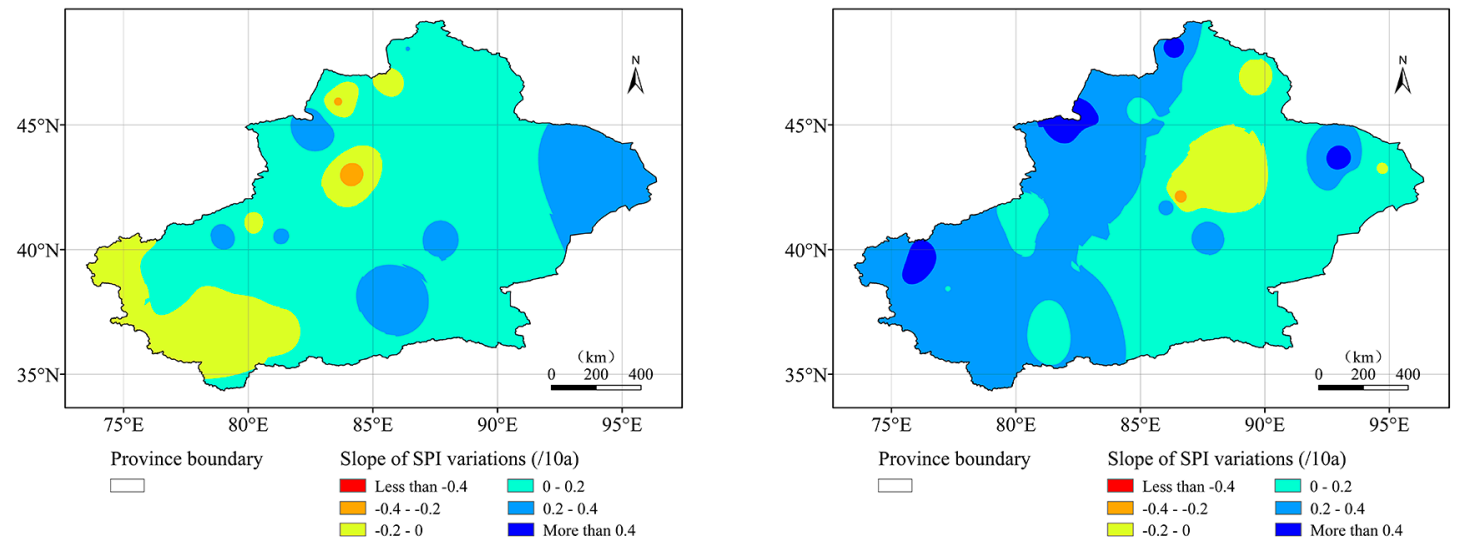

(b) SPI during 1960-1990 (left hand side) and 1991-2018 (right hand side)

Figure 11. The spatial changes of the annual SPEI (a) and the annual SPI (b) during 1960-1990 and 1991-2018.

\subsection{Spatial Variation Characteristics of Drought}

To further analyse the spatial distribution of drought in the study area, the inverse distance weighting interpolation method was applied to interpolate the drought occurrence frequency at each station, subsequently, the distribution of drought frequency across the study area was obtained. Furthermore, the spatial distribution of drought frequency of different grades were compared for the periods of 1960-1996 and 1997-2018 (Figure 12).

Based on Figure 12a, during 1960 to 1996, the frequency of drought was high in the north-west of the study area, with a maximum of $47.11 \%$, while, a lower drought frequency was observed in the south-east region, with the lowest percentage of $5.54 \%$. However, the drought-prone areas shifted from the north-west to the south-east, between 1997 and 2018. Indeed, before the meteorological change, the south-eastern part belonged to the low-incidence drought area in the study area. However, after the meteorological change, drought occurred frequently, with the highest frequency of $84.85 \%$. Although the drought frequency increased throughout the region, the drought centrality shifted from the previous spatial distribution of the drought.

The spatial distribution changes of different types of drought are analysed (see Figure $12 \mathrm{~b}-\mathrm{e}$ ). In 1960-1996, the drought frequency of each type was low and mainly concentrated in the north-west part, which was consistent with the spatial distribution of total drought. Among them, the frequency of mild drought was the highest, which was mainly dominated in the north-west border. The occurrence frequency of moderate and severe drought was lower than that of the mild drought, mainly distributed in the centre of the north-west area. The frequency of extreme drought was the lowest, occurred only 
in the north-west central region and the northern regions, with a maximum of 6.47\%. During 1997 to 2018, an obvious increase was observed in the occurrence frequency of each type of drought, and the areas with the frequent occurrence of mild, moderate, and severe droughts shifted from the north-west to the south-east. The east-central region was identified as the region with the highest frequency of mild drought, with the highest frequency of 34.85\%. Furthermore, the middle region in the south was recognised as the region with the highest frequency of moderate drought, with the highest frequency of $32.95 \%$. The small area in the central region and the area near to the south were identified as the areas with the highest frequency of severe drought (i.e., 32.58\%). The distribution of extreme drought was relatively scattered, mainly distributed in some small areas in the north-central region, with a low frequency, up to $13.64 \%$.
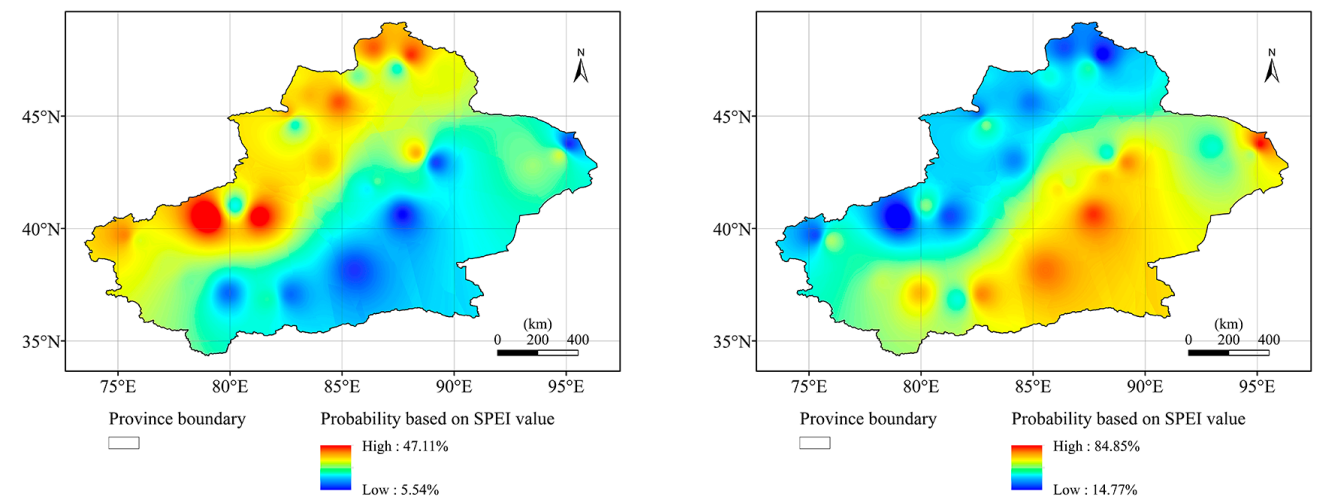

(a)
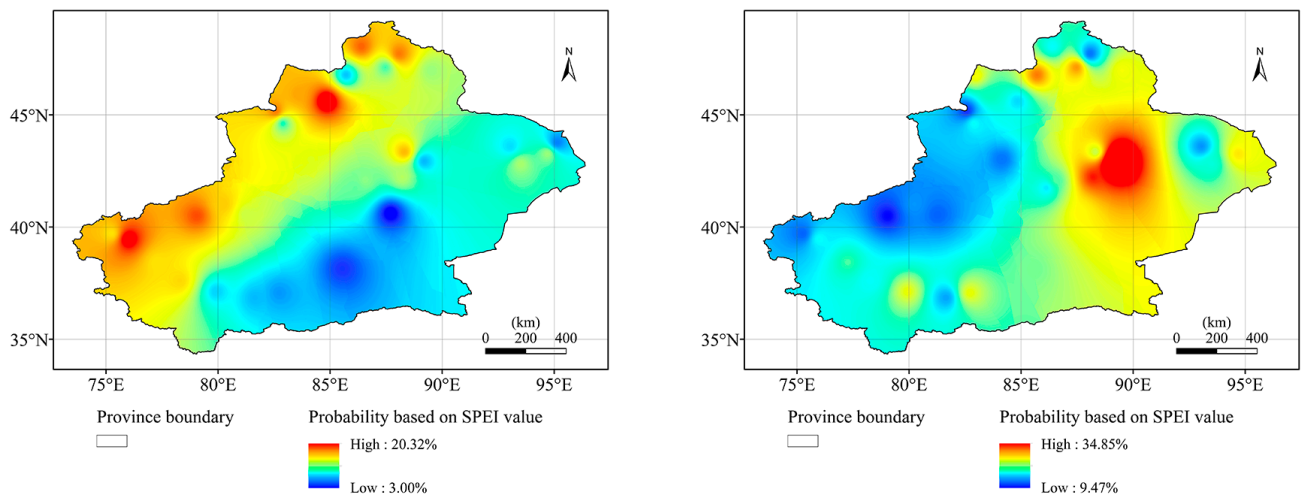

High : $34.85 \%$

(b)
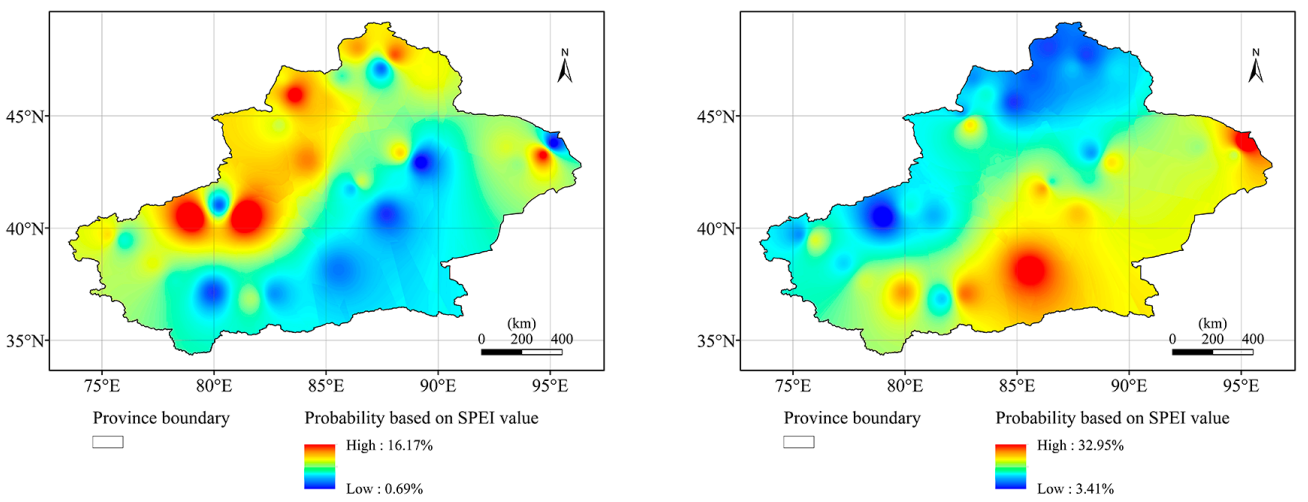

(c)

Figure 12. Cont. 

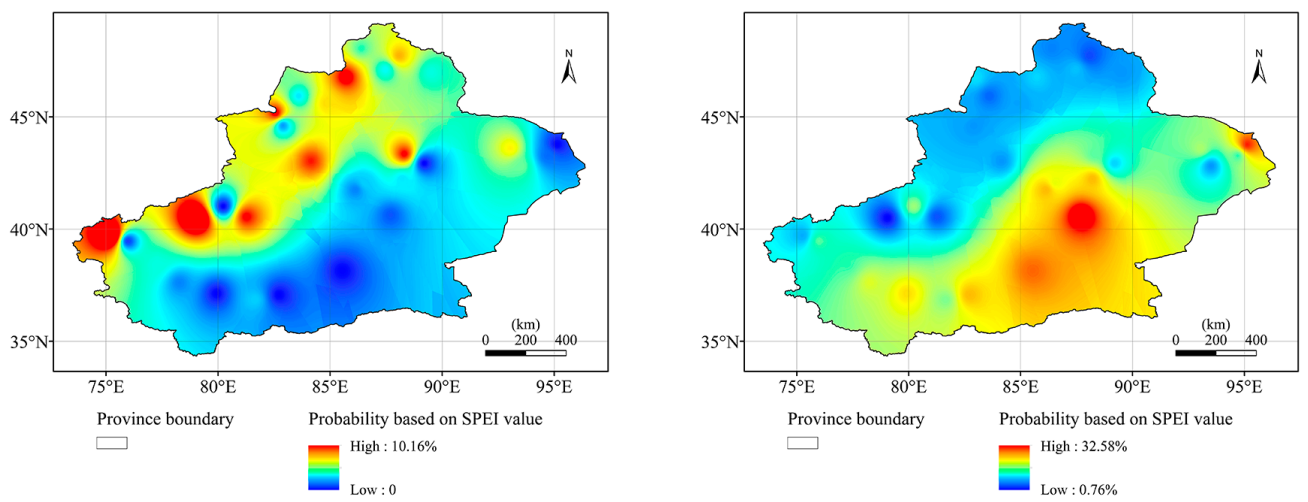

(d)
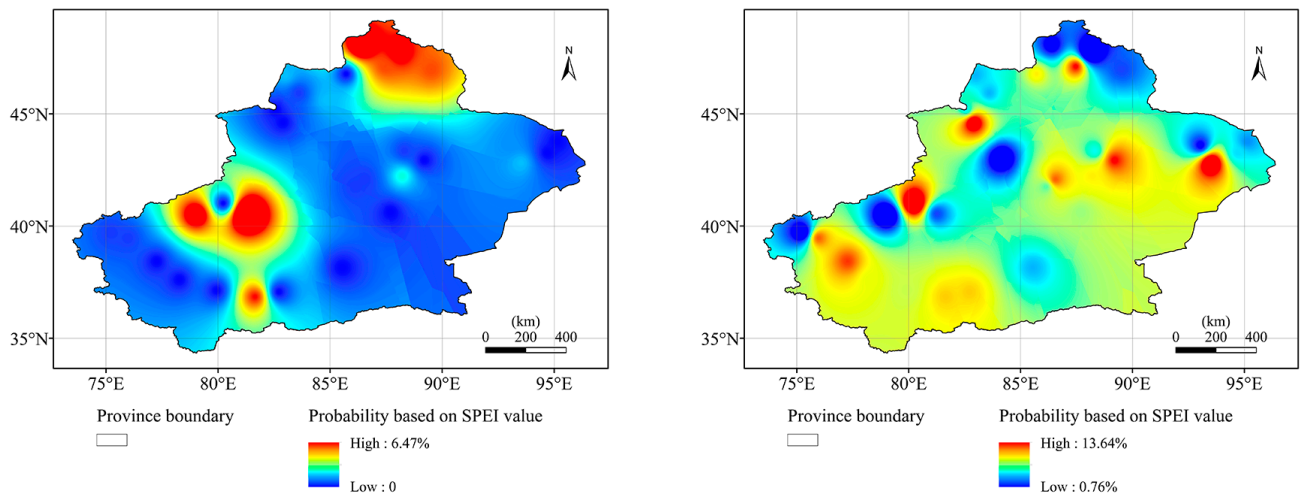

(e)

Figure 12. Spatial distribution of occurrence frequency of drought (a), mild drought (b), moderate drought (c), severe drought (d), and extreme drought (e) during 1960-1996 (left hand side) and 1997-2018 (right hand side).

\section{Conclusions}

In this study, the drought characteristics in Xinjiang was studied to analyse the variation trend, area range, and intra-annual distribution of drought over time. Furthermore, the time point and the reason of the abrupt change of drought situation were discussed, and the drought situation of periods before and after the meteorological change were compared and analysed. The main findings of our research are as follows:

(1) An increasing drought trend was observed across Xinjiang, from 1960 to 2018, while the drought situation rapidly became severe after 1997. The occurrence frequency of drought increased significantly during each annum, as well as the plant growing season, spring, summer, and autumn. The severest drought occurred during 2006 to 2009. In contrast to other seasons, the winter showed a different pattern of drought, starting with a dry climate, followed by a wet climate. Since 2000, the frequency of drought during the winter has declined, significantly. The RDS was used to analyze the effects of duration of the drought and the extent of the drought affected area, which provided a new way to study the actual impact of drought on the environment, agriculture and society. The focus of future research is to find auxiliary indicators that can prove the rationality of existing indexes.

(2) From 1960 to 2018, an expanding trend was identified in the drought area in Xinjiang, while the drought severity was also intensified. From 1960 to 1996, the drought mainly consisted of the mild and the moderate drought, while from 1997 to 2018, the moderate and the severe types of drought were dominant. Except for the decrease of the drought area during winter, the change of the drought area in other seasons and in the plant growing season was consistent with the annual drought trend, showing an expanding trend. 
(3) The annual distribution of drought in Xinjiang also showed obvious time periods. During 1960-1977, the occurrence frequency of drought was higher during January and December and lower during the other months, accompanied with the mild droughts. Since 1978, the drought frequency began to shift throughout the year, gradually concentrating at March to November. The highest frequency of drought occurred during April, and the drought type was mainly dominated by the mild and the moderate drought, with a spot of severe droughts.

(4) During the 1990s, the climate conditions in Xinjiang changed dramatically, with significant increases in precipitation and temperature. However, the increase in temperature was higher than the increase in precipitation, which can be considered as the reason for worsening drought. The aggravation of drought was mainly reflected in more than half of the study area, from south-east to north-west. Since 1997, the frequency, coverage area, and duration of drought in the study area have been significantly increased.

(5) The drought-prone areas shifted from the north-west to the south-east, after the meteorological change. Except for the distribution of extreme drought, which was relatively scattered, obvious regional characteristics were observed in the other types of drought. For instance, the mild drought mainly covered the east-central region, while, the middle part of the southern region experienced the occurrence of moderate drought, and severe drought mainly occurred in the central and central-south regions.

(6) In terms of the temporal-spatial variation characteristics of drought in Xinjiang, appropriate policies should be made by relevant departments for each region. Indeed, considering the spatial distribution of drought, appropriate strategies should be taken for the south-east area, where severe drought is dominant. Taking into account the temporal distribution of drought, the water supply measures should be taken place during April, May and other drought-prone months to ensure the normal progress of the social and economic development, especially the agricultural production.

Author Contributions: Data curation, Q.N.; Formal analysis, J.G.; Funding acquisition, H.H.; Investigation, Y.C.; Methodology, Q.A.; Software, C.W.; Validation, X.X.; Writing-original draft, Q.A.; Writing-review \& editing, H.H. All authors have read and agreed to the published version of the manuscript.

Funding: The study was supported by the National Key Research and Development Program of China (No. 2017YFC0404306), the National Keypoint Research and Invention Program of the thirteenth (No. 2017YFC0404405) and Youth Program of National Natural Science Foundation of China (No. 51709274).

Acknowledgments: We acknowledge to reviewers who helped us in the review process.

Conflicts of Interest: The authors declare no conflict of interest.

\section{References}

1. Yu, M.; Li, Q.; Hayes, M.J.; Svoboda, M.D.; Heim, R.R. Are droughts becoming more frequent or severe in China based on the standardized precipitation evapotranspiration index: 1951-2010? Int. J. Climatol. 2014, 34, 545-558. [CrossRef]

2. Mishra, A.K.; Singh, V.P. A review of drought concepts. J. Hydrol. 2010, 391, 202-216. [CrossRef]

3. Zhang, L.; Zhou, T. Drought over East Asia: A review. J. Clim. 2015, 28, 3375-3399. [CrossRef]

4. Yang, J.; Mei, X.; Huo, Z.; Yan, C.; Hui, J.; Zhao, F.; Qin, L. Water consumption in summer maize and winter wheat cropping system based on SEBAL model in Huang-Huai-Hai Plain, China. J. Integr. Agric. 2015, 14, 2065-2076. [CrossRef]

5. Wang, A.; Lettenmaier, D.P.; Sheffield, J. Soil moisture drought in China, 1950-2006. J. Clim. 2011, 24, 3257-3271. [CrossRef]

6. Wang, L.; Chen, W.; Zhou, W. Assessment of future drought in Southwest China based on CMIP5 multimodel projections. Adv. Atmos. Sci. 2014, 31, 1035-1050. [CrossRef]

7. Lin, W.; Wen, C.; Wen, Z.; Gang, H. Drought in Southwest China: A review. Atmos. Ocean. Sci. Lett. 2015, 8, 339-344.

8. Wenping, Y.; Guangsheng, Z. The oretical study and research prospect on drought indices. Adv. Earth Sci. 2004, 19, 982-991. 
9. McKee, T.B.; Doesken, N.J.; Kleist, J. The relationship of drought frequency and duration to time scales. In Proceedings of the 8th Conference on Applied Climatology, Boston, MA, USA, 1 January 1993; pp. 179-183.

10. Moreira, E.E.; Paulo, A.A.; Pereira, L.S.; Mexia, J.T. Analysis of SPI drought class transitions using loglinear models. J. Hydrol. 2006, 331, 349-359. [CrossRef]

11. Vicente-Serrano, S.M.; Beguería, S.; López-Moreno, J.I. A multiscalar drought index sensitive to global warming: The standardized precipitation evapotranspiration index. J. Clim. 2010, 23, 1696-1718. [CrossRef]

12. Vicente-Serrano, S.M.; Beguería, S.; López-Moreno, J.I.; Angulo, M.; El Kenawy, A. A new global 0.5 gridded dataset (1901-2006) of a multiscalar drought index: Comparison with current drought index datasets based on the Palmer Drought Severity Index. J. Hydrometeorol. 2010, 11, 1033-1043. [CrossRef]

13. Beguería, S.; Vicente-Serrano, S.M.; Reig, F.; Latorre, B. Standardized precipitation evapotranspiration index (SPEI) revisited: Parameter fitting, evapotranspiration models, tools, datasets and drought monitoring. Int. J. Climatol. 2014, 34, 3001-3023. [CrossRef]

14. Beguería, S.; Vicente-Serrano, S.M.; Angulo-Martínez, M. A multiscalar global drought dataset: The SPEIbase: A new gridded product for the analysis of drought variability and impacts. Bull. Am. Meteorol. Soc. 2010, 91, 1351-1356. [CrossRef]

15. Palmer, W.C. Meteorological Drought; US Department of Commerce, Weather Bureau: Washington, DC, USA, 1965; Volume 30.

16. Guttman, N.B. Comparing the palmer drought index and the standardized precipitation index 1. JAWRA J. Am. Water Resour. Assoc. 1998, 34, 113-121. [CrossRef]

17. Hayes, M.J.; Svoboda, M.D.; Wiihite, D.A.; Vanyarkho, O.V. Monitoring the 1996 drought using the standardized precipitation index. Bull. Am. Meteorol. Soc. 1999, 80, 429-438. [CrossRef]

18. Vicente-Serrano, S.M.; Lopez-Moreno, J.-I.; Beguería, S.; Lorenzo-Lacruz, J.; Sanchez-Lorenzo, A.; García-Ruiz, J.M.; Azorin-Molina, C.; Morán-Tejeda, E.; Revuelto, J.; Trigo, R. Evidence of increasing drought severity caused by temperature rise in southern Europe. Environ. Res. Lett. 2014, 9, 044001. [CrossRef]

19. Hernandez, E.A.; Uddameri, V. Standardized precipitation evaporation index (SPEI)-based drought assessment in semi-arid south Texas. Environ. Earth Sci. 2014, 71, 2491-2501. [CrossRef]

20. Li, Y.; Yao, N.; Sahin, S.; Appels, W.M. Spatiotemporal variability of four precipitation-based drought indices in Xinjiang, China. Theor. Appl. Climatol. 2017, 129, 1017-1034. [CrossRef]

21. Allen, K.; Ogden, J.; Buckley, B.; Cook, E.; Baker, P. The potential to reconstruct broadscale climate indices associated with southeast Australian droughts from Athrotaxis species, Tasmania. Clim. Dyn. 2011, 37, 1799-1821. [CrossRef]

22. Potop, V. Evolution of drought severity and its impact on corn in the Republic of Moldova. Theor. Appl. Climatol. 2011, 105, 469-483. [CrossRef]

23. Fuchs, B.; Svoboda, M.; Nothwehr, J.; Poulsen, C.; Sorensen, W.; Guttman, N. A new national drought risk Atlas for the US from the National Drought Mitigation Center; National Drought Mitigation Center, Univ. of Nebraska: Lincoln, NE, USA, 2012.

24. Paulo, A.; Rosa, R.; Pereira, L. Climate trends and behaviour of drought indices based on precipitation and evapotranspiration in Portugal. Nat. Hazards Earth Syst. Sci. 2012, 12, 1481-1491. [CrossRef]

25. Abiodun, B.J.; Salami, A.T.; Matthew, O.J.; Odedokun, S. Potential impacts of afforestation on climate change and extreme events in Nigeria. Clim. Dyn. 2013, 41, 277-293. [CrossRef]

26. Sohn, S.J.; Ahn, J.B.; Tam, C.Y. Six month-lead downscaling prediction of winter to spring drought in South Korea based on a multimodel ensemble. Geophys. Res. Lett. 2013, 40, 579-583. [CrossRef]

27. Zhang, R.; Shang, H.; Yu, S.; He, Q.; Yuan, Y.; Bolatov, K.; Mambetov, B.T. Tree-ring-based precipitation reconstruction in southern Kazakhstan, reveals drought variability since AD 1770. Int. J. Climatol. 2017, 37, 741-750. [CrossRef]

28. Dai, A. Drought under global warming: A review. Wiley Interdiscip. Rev. Clim. Chang. 2011, 2, 45-65. [CrossRef]

29. Zhang, Q.; Tang, H.; Cui, F.; Dai, L. SPEI-based analysis of drought characteristics and trends in Hulun Buir grassland. Acta Ecol. Sin. 2019, 39, 7110-7123.

30. Xuan, J.; Zheng, J.; Liu, Z. SPEI-based spatiotemporal variation of drought in Xinjiang. Arid Zone Res. 2016, 33, 338-344. 
31. Liu, W.; Wang, M.; Ding, J. A test on the palmer drought index with the data collected in the oasis in the northern slope of Tianshan mountain. J. Desert Res. 2013, 33, 249-257.

32. Yao, J.; Zhao, Y.; Chen, Y.; Yu, X.; Zhang, R. Multi-scale assessments of droughts: A case study in Xinjiang, China. Sci. Total Environ. 2018, 630, 444-452. [CrossRef]

33. Jiang, F.; Hu, R. Climate change and flood \& drought disasters in Xinjiang during recent 50 years. J. Desert Res. 2004, 24, 35-40.

34. Jiang, Y.; Zhao, Y.; Chen, Y.; Li, Y. Composite Drought Index CI and Its Application in Xinjiang. Desert Oasis Meteorol. 2010, 4, 18-20.

35. Pan, S.; Zhang, M.; Wang, B.; Li, X. Study on the drought index variation for Xinjiang in recent 51 years. J. Arid Land Resour. Environ. 2013, 27, 32-39.

36. Wang, Z.; Shi, Q.; Wang, T.; Shi, Q.; Chang, S.; Zhang, L. Spatial-temporal characteristics of vegetation cover change in mountain-oasis-desert system of Xinjiang from 1982 to 2006. J. Nat. Resour. 2011, 26, 609-618.

37. Zhang, Q.; Yao, Y.; Li, Y.; Luo, Z.; Zhang, C.; Li, D.; Wang, R.; Wang, J.; Chen, T.; Xiao, G. Research progress and prospect on the monitoring and early warning and mitigation technology of meteorological drought disaster in northwest China. Adv. Earth Sci. 2015, 30, 196-211.

38. Yang, M.; Yan, D.; Yu, Y.; Yang, Z. SPEI-based spatiotemporal analysis of drought in Haihe River Basin from 1961 to 2010. Adv. Meteorol. 2016, 2016, 7685015. [CrossRef]

39. Shen, X.; Wu, X.; Xie, X.; Ma, Z.; Yang, M. Spatiotemporal analysis of drought characteristics in Song-Liao river basin in China. Adv. Meteorol. 2017, 2017, 3484363. [CrossRef]

40. Yuan, W.; Zhou, G. Comparison between standardized precipitation index and Z-index in China. Acta Phytoecol. Sin. 2004, 4, 523-529.

41. Lee, J.H.; Kim, C.J. A multimodel assessment of the climate change effect on the drought severity-duration-frequency relationship. Hydrol. Process. 2013, 27, 2800-2813. [CrossRef]

42. Gocic, M.; Trajkovic, S. Analysis of changes in meteorological variables using Mann-Kendall and Sen's slope estimator statistical tests in Serbia. Glob. Planet. Chang. 2013, 100, 172-182. [CrossRef]

(C) 2020 by the authors. Licensee MDPI, Basel, Switzerland. This article is an open access article distributed under the terms and conditions of the Creative Commons Attribution (CC BY) license (http://creativecommons.org/licenses/by/4.0/). 